Disponible en ligne sur

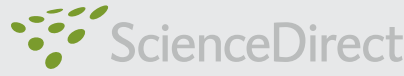

www.sciencedirect.com
Elsevier Masson France

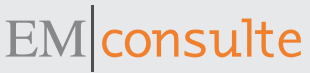

www.em-consulte.com

ORIGINAL ARTICLE / ARTICLE ORIGINAL

\title{
Autonomic aspect of emotional response in depressed patients: Relationships with personality
}

\section{Réponse émotionnelle autonome chez le patient déprimé : relations avec la personnalité}

\section{S. Mardaga*, M. Hansenne}

Department of Cognitive Sciences, Faculty of Psychology, University of Liège, 5, boulevard du Rectorat (B32), 4000 Liège, Belgique

Received 27 January 2009; accepted 22 June 2009

Available online 16 July 2009

\section{KEYWORDS \\ Depression; \\ Personality; \\ Emotions; \\ Skin conductance \\ response}

\begin{abstract}
Summary
Study aim. - Affective symptoms are major descriptors of depression; therefore, a lot of studies investigated emotional-responsiveness modulation in depression, and reported either a potentiation of negative affects, a reduction of positive affects, or a reduction of both positive and negative affects. On the other hand, personality was classically found to be modulated in depression, with behavioral inhibition system (BIS)-related dimensions (namely harm avoidance (HA), neuroticism) showing higher scores in depressed subjects. The aim of this study was to investigate the relationships between emotional responsiveness (as measured by skin conductance response $[\mathrm{SCR}]$ ) and personality in depression.

Methods. - SCR was recorded following the presentation of neutral, pleasant, and unpleasant pictures in 20 depressed subjects and 20 controls.

Results. - Pleasant pictures elicited more and larger responses than unpleasant ones in control but not in depressed subjects. This effect was not modulated by personality. Moreover, depressed subjects were found to show generally faster half-recovery times and to rate emotional pictures as less arousing than control subjects and these effects disappeared when BIS-related dimensions were controlled.

Conclusions. - These results suggest that BIS-related dimensions are independent from the specifically reduced responses to pleasant pictures, but are involved in the observed general affect reducing.

(c) 2009 Elsevier Masson SAS. All rights reserved.
\end{abstract}

\footnotetext{
* Corresponding author.

E-mail address: solange.mardaga@student.ulg.ac.be (S. Mardaga).
} 


\section{MOTS CLÉS \\ Dépression ; \\ Personnalité ; \\ Émotions ; \\ Réponse \\ électrodermale}

\section{Résumé}

Objectifs. - Les symptômes affectifs sont des descripteurs majeurs de l'épisode dépressif ; pour cette raison, un grand nombre de travaux ont étudié les modulations de la réactivité émotionnelle dans la dépression. Ils rapportent une potentialisation des affects négatifs, une diminution des affects positifs ou une réduction à la fois des affects positifs et négatifs. Par ailleurs, la personnalité est classiquement modulée dans la dépression, de sorte que les scores aux dimensions associées au système d'inhibition comportementale (SIC) (i.e. évitement du danger, neuroticisme) sont plus élevés chez les sujets déprimés. Le but de notre étude était d'investiguer les relations entre la réactivité émotionnelle (mesurée par la réponse électrodermale [RED]) et la personnalité dans la dépression.

Méthodes. - La RED a été enregistrée suite à la présentation d'images neutres, plaisantes et déplaisantes chez 20 sujets déprimés et 20 sujets contrôles.

Résultats. - Les images plaisantes provoquent plus de réponses et des réponses plus amples que les images déplaisantes chez les sujets contrôles mais pas chez les déprimés. Cet effet n'est pas modulé par la personnalité. Par ailleurs, les sujets déprimés montrent des temps de récupération plus courts et jugent les images émotionnelles comme associées à un éveil émotionnel moindre que les sujets contrôles et ces effets disparaissent lorsque les dimensions associées au SIC sont contrôlées.

Conclusions. - Ces résultats suggèrent que les dimensions associées au SIC sont indépendantes de la diminution sélective des réponses aux images plaisantes mais sont impliquées dans la réduction globale observée des affects.

(c) 2009 Elsevier Masson SAS. Tous droits réservés.

\section{Introduction}

Affective symptoms, namely anhedonia (i.e. loss of interest and pleasure) and negative affects (sadness, self unvalorization, and guilt) are major descriptors of depressive disorders [2]. These symptoms attest both increased negative affects and/or decreased positive affects in depressive disorders. Regarding the importance of affective symptoms in depressive disorders, emotional responsiveness in depressed patients is of major interest to understand this disorder, therefore numerous studies investigated emotional responsiveness in depressed patients, including somatic emotional responsiveness (skin conductance responses [SCR], heart rate and blood pressure changes, breathing response). Some of these report either increased negative affects [31,43], decreased positive affects [43], or an overall decreased emotional responsiveness (i.e. a decrease in both positive and negative affects $[1,16,28,38-40])$. A recent metaanalysis conducted over 19 studies concluded that both negative and positive affects would be reduced in major depressive disorders, with positive affects being the most reduced, irrespective of the measured response (reported affects, expressive response, and peripheral response) [6].

On the other hand, depressive disorders have been extensively studied as regard to personality, in order to reveal trait- (i.e. vulnerability factors) as well as statemarkers of this condition. Several studies found increased scores in both neuroticism and harm avoidance (HA) during depressive episodes [25,26,36]; these modifications are consistent with behavioral changes (as well as behavioral tendencies changes) classically observed in depressive disorder (behavioral inhibition, tiredness...), which are relevant as regard to behavioral inhibition sensitivity (BIS)-related personality scales $[11,12]$. Moreover, it was shown that high neuroticism/HA scores measured during depressive episode decrease in discharged patients (i.e. after the episode), while remaining higher than in healthy patients $[26,36]$. A high score in BIS-related dimensions might also constitute a vulnerability factor, as suggested by the relationship between HA score and depressed mood one year later [10]. Thus, behavioral inhibition observed in depressive disorder might be reflected in BIS-related personality dimension scores. Moreover, BIS-related personality scales were related to negative affects, and responsiveness to unpleasant stimuli, considering self-reported affects (e.g. $[14,23,27,41])$, cognitive processing (e.g. [18-21]) as well as somatic responses (e.g. $[13,18-20,32,33])$.

This study aimed to investigate relationships between personality change and emotional responsiveness in depressed patients. More precisely, we wanted to investigate whether somatic emotional response modulations in depressive disorder could be partly explained by changes in BIS-related personality dimensions (namely neuroticism, HA, BIS scale, and sensitivity to punishment scale $[7,8,15,22,46])$. Somatic emotional responses will be assessed by recording SCR, which is a classical and sensitive index of affective arousal $[5,17]$, which directly reflects sympathetic nervous system activity (i.e. autonomic emotional response) and has been largely used in emotion research $[32,33,42]$.

\section{Methods}

\section{Subjects}

The study was conducted in 20 depressed subjects (nine males; age ranging from 22 to 59 years) and 20 age- and gender-matched controls (nine males; age ranging from 24 to 59 years). Depressed subjects were recruited in the 
psychiatric unit of CHR Citadelle, Liège, where they had been diagnosed for major depression according to DSM IV criteria [2]. Controls were free from psychiatric and somatic diseases as evidenced by a clinical interview; the use of any drug (with the exception of contraceptive pill) was excluded in control subjects. All subjects had normal or corrected-tonormal vision and were naive to the aim of the experiment and to the pictures that were used in the experiment. The protocol was approved by the ethical committee of the University of Liège Psychology Faculty, and the subjects gave their informed consent to participate in the study.

The participants completed the French version of the revised form of the Temperament and Character Inventory (TCl-R $[9,24])$, of the Neuroticism Extraversion Openness personality inventory (NEO-PI-R [15]), of the BIS/BAS scales [7], and of the sensitivity to punishment and sensitivity to reward questionnaire (SPSRQ [46]). They also completed a French version of the Beck Depression Inventory (BDI) II [4]; all depressed subjects showed BDI-scores between 15-48 (light to severe depression), and control subjects scored between 0-9 (i.e. no depression).

\section{Visual stimuli}

Visual stimuli consisted of 30 pictures (ten neutral, ten pleasant and ten unpleasant), selected from the international affective picture system (IAPS [30]). The pictures were presented on a 17-inch computer screen (rate of refreshment, $85 \mathrm{~Hz}$ ), and the subjects sat in front of the screen at a distance of $0.5 \mathrm{~m}$. Pictures were presented for 5 seconds and were separated by a black screen with a white cross at the center lasting 10 seconds. During this 10 seconds period, the subjects were asked to rate on 9-point Likert scales the emotional valence $(1=$ low pleasure to $9=$ high pleasure) and the arousal of the previous picture (1=low arousal to $9=$ high arousal).

\section{Procedure}

Subjects first completed the personality scales, the BDI-II, the mood scale, and the arousal scale. They were comfortably installed and electrodes were placed. After an accommodation period of 20 minutes, the pictures were presented to the subjects while the SCR were recorded. The pictures were displayed in a pseudo-randomized order so that two slides from the same category could not follow each other. The recording session lasted about 9 minutes.

\section{SCR recording and analysis}

SCR were recorded in a sound-attenuated room with a $23^{\circ} \mathrm{C}$ ambient temperature using a SC5 (Psylab) system (DC, constant voltage $0.5 \mathrm{v}$, conductance measure). Disposable $\mathrm{Ag} / \mathrm{AgCl}$ electrodes were attached to the last phalange of the third and fourth fingers of the non-dominant hand. A $0.05-M$ sodium chloride conductive gel was incorporated into electrodes.

SCR were analyzed individually for a 10 seconds period from picture onset and responses were selected as the first wave in a time window between 1 and 4 seconds for rise latency, and whose peak amplitude reached $0.04 \mu \mathrm{S}$ [17]. Mean amplitude, response frequency and mean halfrecovery time were calculated for each picture category, and amplitude and half-recovery time values were logarithmically transformed to fit normal distribution.

\section{Statistical analysis}

All the statistical analyses were performed with Statistica (8) for Windows. Student's $t$ tests were conducted between depressed and control groups regarding age and BDI-II score. For each personality model tested, a MANOVA was conducted with two groups (depressed vs. control) as the independent variable and with personality dimensions as the dependent variables. Regarding SCR data and picture ratings, two-way repeated-measures ANOVA two groups (depressed vs. control) $\times 3$ picture categories (neutral, pleasant, unpleasant) were performed, with picture category as the within-subject factor, with amplitude, response frequency, half-recovery time, rated pleasure and arousal as dependent variables. Furthermore, in order to investigate the interactions between SCR, depression, and personality data, the same analyses were conducted with dimensions relevant to negative affects sensitivity (namely HA, neuroticism, SP scale and BIS score) added as covariate. All effects involving repeated measurements were corrected by Greenhouse-Geisser epsilon for lack of sphericity, and Student's $t$ tests were used as post-hoc analysis. Pearson's correlations (with Bonferroni correction) were conducted between personality scores and SCR parameters.

\section{Results}

Student's $t$ tests showed that depressed subjects scored higher for the BDI-II than controls (Table 1). Moreover, MANOVA showed a significant main effect of group regarding each model tested (TCl: $F_{[7,32]}=4.15, p<0.005$; BIS/BAS: $F_{[2,37]}=3.41, \quad p<0.005 ; \quad \mathrm{NEO}-\mathrm{PI}: \quad F_{[5,34]}=4.98, \quad p<0.005$; SPSRQ: $\left.F_{[2,37]}=7.33, p<0.005\right)$, with depressed subjects showing higher scores for the HA, BIS, Neuroticism, SP and $\mathrm{SR}$, and scoring lower for self-directedness and consciousness scales (Table 1). No significant Pearson's correlation was found between personality scores and SCR parameters (Table 2).

ANOVA conducted with response frequency as the dependent variable showed a main effect of picture category $\left(F_{[2,76]}=7.68, p=0.001\right)$, reflecting that pleasant and unpleasant pictures induced more responses that neutral ones $\left(t_{[38]}=4.75, p<0.001 ; t_{[38]}=4.62, p<0.001\right)$. Although the group $\times$ picture category did not reach significance $\left(F_{[2,76]}=0.99, p=0.37\right)$ but because of specific expectations regarding emotional differences between depressed and control subjects, paired comparisons were carried out, and showed that pleasant pictures elicited more responses than the unpleasant ones in control $\left(t_{[38]}=2.66, p=0.01\right)$ but not in depressed subjects $\left(t_{[38]}=0.11, p=0.91\right)$. These effects were not modulated when relevant personality score were controlled.

ANOVA conducted with response amplitude as the dependent variable showed a main effect of picture category 
Table 1 Mean (SD) age, BDI-II score, and personality scores for depressed and control subjects, and results of comparisons performed between groups.

\begin{tabular}{lllcr}
\hline & Control & Depressed & $t(\mathrm{df}=38)$ & $p$ \\
\hline Age & $42.8(11.51)$ & $42.7(11.25)$ & -0.04 & 0.97 \\
BDI-II & $3.95(2.67)$ & $32.95(10.87)$ & -11.58 & 0.0001 \\
Novelty Seeking & $99.70(11.69)$ & $95.75(12.50)$ & -1.03 & 3.73 \\
Harm Avoidance & $95.15(15.83)$ & $117.90(22.18)$ & 0.52 & 0.31 \\
Reward Dependence & $100.95(12.09)$ & $103.30(16.07)$ & 0.05 & 0.60 \\
Persistence & $111.05(19.49)$ & $111.45(25.93)$ & -3.16 & 0.96 \\
Self Directedness & $142.55(19.34)$ & $123.50(18.79)$ & -1.46 & 0.005 \\
Cooperation & $136.25(10.71)$ & $128.80(20.19)$ & -0.51 & 0.15 \\
Self Transcendence & $79.25(10.82)$ & $77.35(12.49)$ & -2.37 & 0.02 \\
BIS & $20.45(3.73)$ & $23.20(3.61)$ & -1.70 & 0.10 \\
BAS & $36.85(5.27)$ & $39.65(5.11)$ & -5.02 & 1.28 \\
Neuroticism & $86.10(24.34)$ & $124.10(23.55)$ & 1.49 & 0.0001 \\
Extraversion & $100.00(17.71)$ & $92.85(17.64)$ & -0.39 & 0.14 \\
Openness & $113.25(16.45)$ & $104.40(20.81)$ & 2.12 & 0.70 \\
Agreeableness & $125.70(14.25)$ & $127.75(18.51)$ & -2.90 & 0.04 \\
Consciousness & $113.60(16.96)$ & $101.05(20.25)$ & -2.65 & 0.01 \\
Sensitivity to Punishment & $9.85(6.31)$ & $15.20(5.31)$ & & 0.01 \\
Sensitivity to Reward & $6.25(3.37)$ & $9.40(4.11)$ & & \\
\hline
\end{tabular}

$\left(F_{[2,76]}=17.34, \quad p<0.0001\right)$, reflecting that pleasant pictures induced larger responses than neutral and unpleasant ones $\left(t_{[38]}=3.79, p<0.001 ; t_{[38]}=2.33, p=0.03\right)$. Although the group $\times$ picture category did not reach significance $\left(F_{[2,76]}=1.82, \quad p=0.18\right)$, paired comparisons showed that pleasant pictures elicited larger responses than the unpleasant ones in controls $\left(t_{[38]}=2.76, p<0.01\right)$ but not in depressed subjects $\left(t_{[38]}=0.54, p=0.59\right)$. These effects were not modulated when relevant personality scores were controlled (Fig. 1).

ANOVA conducted with response half-recovery times as the dependent variable showed a main effect of picture category $\left(F_{[2,76]}=4.97, p=0.01\right)$, reflecting that pleasant pictures induced longer-lasting responses than neutral and unpleasant ones $\left(t_{[38]}=2.48, p=0.02 ; t_{[38]}=3.28, p=0.002\right)$, and a main effect of the group $\left(F_{[1,38]}=4.42, p=0.042\right)$ with depressed subjects showing generally shorter halfrecovery times than controls. Although the group $\times$ picture category did not reach significance $\left(F_{[2,66]}=0.57, p=0.55\right)$, paired comparisons showed that pleasant pictures elicited longer half-recovery times than the unpleasant ones in controls $\left(t_{[38]}=3.24, p=0.002\right)$ but not in depressed subjects $\left(t_{[38]}=1.39, p=0.17\right)$. When $\mathrm{HA}$ was controlled, the above described main effect of group disappeared $\left(F_{[1,37]}=0.97, \quad p=0.33\right)$, as well as when neuroticism $\left(F_{[1,37]}=0.66, \quad p=0.42\right)$, and SP $\left(F_{[1,37]}=2.18 p=0.15\right)$, but not BIS $\left(F_{[1,37]}=4.43, \quad p=0.04\right)$ were controlled (Fig. 2).
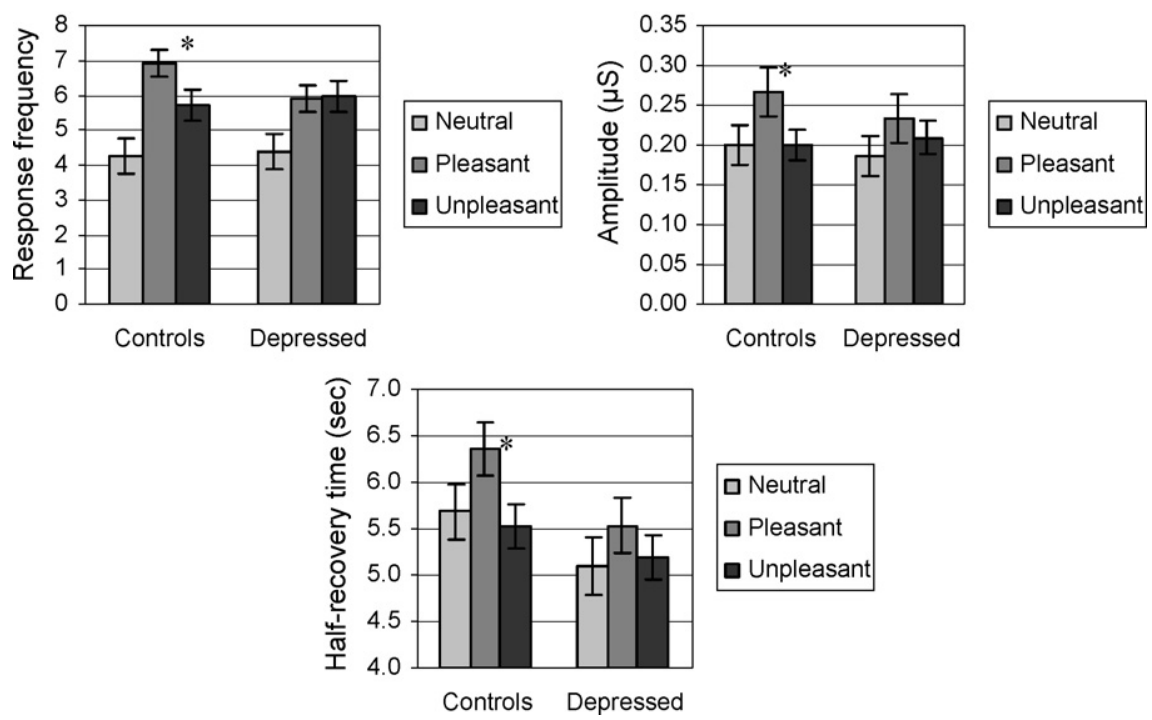

Figure 1 Mean (SEM) frequency, amplitude, and half-recovery times for neutral, pleasant and unpleasant pictures, in control and depressed subjects. * indicates a significant difference at 0.05 threshold. 
Table 2 Pearson's correlations between personality dimensions and SCR parameters in control and depressed subjects.

\begin{tabular}{|c|c|c|c|c|c|c|c|c|c|}
\hline \multirow{2}{*}{$\begin{array}{l}\text { Control } \\
\text { Depressed }\end{array}$} & \multicolumn{3}{|c|}{ Frequency } & \multicolumn{3}{|c|}{ Amplitude } & \multicolumn{3}{|c|}{ Half-recovery time } \\
\hline & Neu & Pleas & Unpl & Neu & Pleas & Unpl & $\mathrm{Neu}$ & Pleas & Unpl \\
\hline \multirow[t]{2}{*}{ Novelty seeking } & -0.19 & -0.06 & -0.10 & -0.07 & -0.32 & -0.16 & 0.09 & -0.11 & 0.09 \\
\hline & -0.21 & 0.15 & 0.02 & -0.27 & -0.03 & -0.19 & 0.31 & 0.20 & 0.44 \\
\hline \multirow[t]{2}{*}{ Harm avoidance } & -0.11 & -0.06 & 0.18 & -0.21 & 0.23 & 0.16 & -0.33 & 0.37 & 0.18 \\
\hline & 0.27 & 0.00 & 0.19 & 0.02 & 0.12 & 0.11 & -0.49 & -0.22 & -0.39 \\
\hline \multirow[t]{2}{*}{ Reward dependence } & -0.11 & 0.28 & 0.08 & 0.11 & 0.15 & -0.28 & -0.05 & 0.16 & 0.38 \\
\hline & -0.21 & -0.43 & -0.30 & -0.22 & -0.30 & -0.21 & 0.30 & 0.16 & 0.48 \\
\hline \multirow[t]{2}{*}{ Persistence } & -0.07 & 0.14 & -0.14 & 0.05 & 0.19 & 0.06 & 0.30 & 0.05 & -0.05 \\
\hline & -0.44 & -0.00 & -0.25 & -0.12 & -0.14 & -0.22 & 0.41 & 0.48 & 0.33 \\
\hline \multirow[t]{2}{*}{ Self directedness } & -0.07 & -0.05 & -0.22 & -0.08 & -0.07 & -0.17 & 0.26 & -0.01 & -0.10 \\
\hline & -0.15 & -0.10 & -0.47 & 0.04 & -0.20 & -0.01 & -0.02 & 0.44 & 0.56 \\
\hline \multirow[t]{2}{*}{ Cooperation } & -0.28 & 0.07 & -0.47 & -0.14 & 0.05 & -0.16 & -0.06 & 0.07 & 0.26 \\
\hline & -0.34 & -0.06 & -0.33 & 0.26 & 0.06 & 0.05 & 0.06 & 0.05 & 0.32 \\
\hline \multirow[t]{2}{*}{ Self transcendence } & -0.04 & -0.04 & -0.31 & 0.16 & 0.01 & 0.01 & 0.12 & -0.17 & 0.07 \\
\hline & -0.22 & -0.04 & -0.12 & 0.39 & 0.09 & -0.02 & 0.44 & -0.22 & -0.15 \\
\hline \multirow[t]{2}{*}{ BIS } & 0.11 & -0.01 & 0.14 & 0.12 & 0.38 & 0.28 & -0.06 & 0.24 & 0.38 \\
\hline & 0.18 & -0.02 & 0.12 & -0.09 & 0.08 & 0.06 & -0.04 & 0.08 & -0.24 \\
\hline \multirow[t]{2}{*}{ BAS } & -0.13 & -0.13 & -0.17 & 0.05 & -0.01 & -0.07 & 0.11 & 0.08 & 0.14 \\
\hline & -0.12 & -0.46 & -0.24 & -0.36 & -0.35 & -0.12 & 0.40 & 0.15 & 0.31 \\
\hline \multirow[t]{2}{*}{ Extraversion } & -0.20 & 0.13 & -0.18 & 0.16 & -0.06 & -0.27 & 0.27 & -0.02 & 0.08 \\
\hline & -0.00 & -0.16 & 0.13 & 0.11 & 0.08 & 0.00 & 0.50 & 0.09 & 0.33 \\
\hline \multirow[t]{2}{*}{ Neuroticism } & 0.03 & 0.19 & 0.14 & 0.01 & 0.17 & 0.21 & -0.34 & 0.16 & 0.05 \\
\hline & -0.05 & 0.04 & -0.01 & -0.17 & -0.05 & -0.12 & -0.30 & -0.11 & -0.39 \\
\hline \multirow[t]{2}{*}{ Openness } & -0.14 & 0.09 & -0.37 & 0.14 & -0.02 & 0.04 & 0.02 & -0.19 & -0.10 \\
\hline & -0.36 & 0.33 & 0.01 & 0.22 & 0.35 & 0.45 & -0.18 & 0.02 & -0.01 \\
\hline \multirow[t]{2}{*}{ Agreeableness } & -0.07 & 0.09 & -0.30 & -0.01 & 0.17 & -0.32 & 0.00 & 0.18 & 0.20 \\
\hline & -0.30 & 0.16 & -0.36 & 0.40 & 0.17 & 0.04 & 0.07 & 0.00 & 0.09 \\
\hline \multirow[t]{2}{*}{ Consciousness } & -0.30 & 0.03 & -0.29 & -0.14 & -0.03 & -0.11 & 0.39 & 0.14 & 0.13 \\
\hline & 0.03 & 0.02 & -0.16 & -0.02 & -0.11 & 0.14 & -0.02 & 0.48 & 0.29 \\
\hline \multirow[t]{2}{*}{ Sensitivity to punishment } & 0.02 & 0.17 & 0.12 & -0.11 & 0.32 & 0.22 & -0.23 & 0.28 & 0.27 \\
\hline & 0.18 & 0.01 & 0.22 & -0.04 & 0.10 & 0.08 & -0.21 & -0.22 & -0.64 \\
\hline \multirow[t]{2}{*}{ Sensitivity to reward } & 0.03 & 0.26 & 0.04 & 0.11 & -0.02 & 0.06 & 0.16 & -0.06 & -0.12 \\
\hline & -0.38 & -0.48 & -0.15 & -0.18 & -0.22 & -0.03 & 0.19 & -0.13 & 0.11 \\
\hline
\end{tabular}

No correlation significant ( 0.05 threshold). Neu: neutral; pleas: pleasant; unpl: unpleasant.

ANOVA conducted with subjective pleasure as the dependent variable showed a main effect of picture category $\left(F_{[2,76]}=87.40, p<0.0001\right)$, with significant differences between all picture categories (neutral-pleasant:

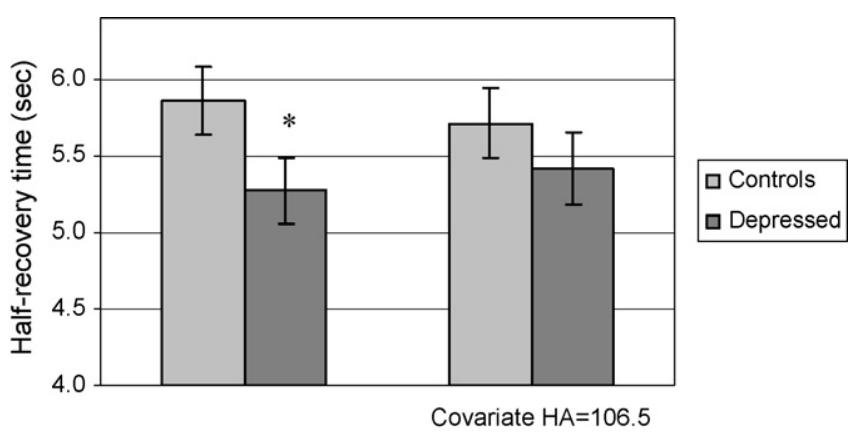

Figure 2 Mean (SEM) half-recovery time recorded in control and depressed subjects without (left) and with (right) controlling harm avoidance score. * indicates a significant difference at 0.05 threshold. $t_{[38]}=5.63, \quad p<0.0001 ; \quad$ neutral-unpleasant: $t_{[38]}=9.58$, $p<0.001$; pleasant-unpleasant: $\left.t_{[38]}=11.88, p<0.0001\right)$. These effects were not modulated when relevant personality score were controlled.

ANOVA conducted with subjective arousal as the dependent variable showed a main effect of picture category $\left(F_{[2,76]}=21.83, p<0.0001\right)$, with significant differences between neutral and pleasant pictures $\left(t_{[38]}=5.30\right.$, $p<0.0001)$ and between neutral and unpleasant ones $\left(t_{[38]}=5.97, p<0.0001\right)$, a main effect of group $\left(F_{[1,38]}=4.97\right.$, $p=0.03$ ) showing that depressed subjects rate pictures as generally less arousing than control subjects, and a significant group $\times$ picture category interaction $\left(F_{[2,76]}=6.32\right.$, $p=0.003$ ), showing that depressed subjects rated unpleasant $\left(t_{[38]}=3.35, p=0.002\right)$ and tended to rate pleasant pictures $\left(t_{[38]}=1.72, p=0.09\right)$ as less arousing than control subjects, but not the neutral ones $\left(t_{[38]}=0.69, p=0.50\right)$. When HA was controlled, the main effect of group disappears $\left(F_{[1,37]}=1.50, p=0.23\right)$, as well as when neuroti$\operatorname{cism}\left(F_{[1,37]}=2.63, p=0.11\right)$, and BIS $\left(F_{[1,37]}=2.25, p=0.14\right)$ were controlled, but the main effect of group remains 
as a tendency when SP was controlled $\left(F_{[1,37]}=3.72\right.$, $p=0.06$ ).

\section{Discussion}

The aim of this experiment was to investigate the role of personality in autonomic emotional reactivity modulation in depression. The results showed that response amplitude and frequency were modulated in depression: while pleasant pictures elicited more and larger responses than unpleasant ones in control subjects, this was not the case in depressed subjects. This suggests that depression modulates the weight of pleasant and unpleasant stimuli, as measured through autonomic responses, which is consistent with previous reports of decreased positive affects in depression [44] as well as with classically observed anhedonia symptom of depression [2]. The same effect is observed with half-recovery times as the dependent variable: pleasant pictures elicited longer half-recovery times than unpleasant ones in controls, but not in depressed subjects. Since half-recovery time is assumed to reflect either a mere index of response dissipation or attentional process, namely attention focusing to the attended stimuli (with short recovery time reflecting open attention to the environment, whereas longer recovery time would reflect more focused attention to the target $[5,35,47])$, this result suggests either a faster dissipation of responses to pleasant pictures, or a selective deficit of attentional focusing on pleasant stimuli as compared to unpleasant ones, in depressed subjects as opposed to controls. Moreover, depressed subjects showed generally shorter half-recovery times than controls. If this parameter is considered as an attentional focus index, this result may be a further indication of the sustained attention difficulty classically observed in depressed subjects, among other cognitive deficits $[3,34]$. This attentional focusing deficit might also play a role in the global affective reduction reported by some authors $[38,40]$. Finally, regarding subjective rating of pictures, arousal was generally lower in depressed subjects, and more particularly, it was shown to be lower for both unpleasant and pleasant pictures (tendency), suggesting a global reduction of self-reported emotion intensity. By opposition, self-reported pleasure was not modulated by depression, indicating that valence evaluation is intact.

As a whole, these results support both the selective positive affect reduction hypothesis [44], as pleasant pictures elicited more and larger responses, and longer half-recovery times than unpleasant ones in control but not in depressed subjects, and the overall emotional reduction hypothesis (i.e. emotion context insensitivity hypothesis, $\mathrm{ECl}$ [38]), as depressed subjects show generally lower self-reported arousal and shorter half-recovery times than controls. None of the result supports the increased negative affects hypothesis, consistently with the results from the recent meta-analysis about the influence of depression on emotional reactivity [6].

Regarding personality influence (namely BIS-related dimensions) in emotional modulation in depression, the results show two aspects. The above-reported results are not modified when BIS-related dimensions are controlled, so that personality does not seem implicated in the specific reduction in autonomic responsiveness to pleasant stimuli. This suggests that specific emotional responsiveness modulation (namely reduced positive affects) and personality changes in depression do not share variance and are thus largely independent phenomena.

On the other hand, when BIS-related dimensions were controlled, the influence of depression on half-recovery times disappears, suggesting that personality is involved in the general shortening of half-recovery times observed in depression. Recently, shorter half-recovery times were reported in high-HA subjects as compared to low-HA ones [32]; taken together, these results suggest that traitanxiety may be related to less attentional focusing (but environment-open attention) which might be more pronounced in depression, possibly through an increased BIS sensitivity. As well, when BIS-related dimensions were controlled, the influence of depression on arousal disappears, suggesting that these personality dimensions are involved in the global lowering of self-reported emotion intensity observed in depression. According to $\mathrm{ECl}$ hypothesis, depression (depressive mood) could be a global defensive insensitization to the whole environment that might be adaptive while allowing the individual to disengage from situations where it would be useless or dangerous to keep on acting (e.g., inaccessible goals $[29,38]$ ). To this view, it is consistent that this supposed-defensive aspect of depression might be related to other defensive phenomena potentiation, such as behavioral inhibition tendencies as measured by the BIS-related personality scores.

The principal limitation of this study is the lack of some data such as the particular form of depression, medication, possible comorbidities, and hospitalization length, which may contribute to some heterogeneity in the group of depressed subjects. More particularly, regarding comorbidities, since state-anxiety was shown to influence emotional stimulus processing $([37,45])$, including an anxiety scale might have helped understand the reported data. Another limitation to the conclusions would be the lack of significance regarding group $\times$ picture category interactions, although paired comparisons showed differences between groups. However, this study is the first one, to our knowledge, to investigate relationships between personality and emotional responsiveness in depression, and its results bring a new and interesting lightening to this issue. It might be useful to follow this line of research while addressing other aspect of the emotional response, such as cognitive processing of emotional material in depressed patients.

To summarize, our results support both lower positive affects hypothesis (regarding electrophysiological data) and $\mathrm{ECI}$ hypothesis (self-reported arousal and half-recovery times) in depression. BIS-related dimensions did not modulate the specifically reduced responses to pleasant pictures, but seem to be involved in the observed general affect reducing and attention-focusing difficulty.

\section{Conflicts of interest}

None. 


\section{Acknowledgements}

We thank François Valkenborgh for his technical support.

\section{References}

[1] Albus M, Muller-Spahn F, Ackenheil M, Engel RR. Psychiatric patients and their response to experimental stress. Stress Med 1987;3:233-8.

[2] American Psychiatric Association. Diagnostic and statistical manual of mental disorders. 4th ed. Washington, DC: Author; 1994.

[3] Austin MP, Mitchell P, Wilhelm K, Parker G, Hickie I, Brodaty $\mathrm{H}$, et al. Cognitive function in depression: a distinct pattern of frontal impairment in melancholia? Psychol Med 1999;29:73-85.

[4] Beck AT, Steer RA, Brown GK. Manual for the Beck Depression Inventory. 2nd ed. San Antonio, TX: Psychological Corporation, Harcourt, Brace; 1996.

[5] Boucsein W. Electrodermal activity. New York: Plenum press; 1992.

[6] Bylsma LM, Morris BH, Rottenberg J. A meta-analysis of emotional reactivity in major depressive disorder. Clin Psychol Rev 2008;28:676-91.

[7] Carver CS, White TL. Behavioral inhibition, behavioral activation, and affective responses to impeding reward and punishment: the BIS/BAS scales. J Pers Soc Psychol 1994;67:319-33.

[8] Cloninger CR. A systematic method for clinical description and classification of personality variants. Arch Gen Psychiatr 1987;44:573-88.

[9] Cloninger CR. The Temperament, Character, InventoryRevised. Center for psychobiology of personality, Washington University, St-Louis: Missouri; 1999.

[10] Cloninger CR, Svrakic DM, Przybeck TR. Can personality assessment predict future depression? A 12-month follow-up of 631 subjects. J Affect Disord 2006;92:35-44.

[11] Corr PJJA. Gray's reinforcement sensitivity theory: tests of the joint subsystem hypothesis of anxiety and impulsivity. Personality and Individual Differences 2002;33:511-32.

[12] Corr PJ. Reinforcement sensitivity theory and personality. Neurosci Biobehav Rev 2004;28:317-32.

[13] Corr PJ, Kumari V, Wilson GD, Checkey S, Gray JA. Harm avoidance and affective modulation of the startle reflex: a replication. Personality and Individual Differences 1997;22:591-3.

[14] Costa PT, McCrae RR. Influence of extraversion and neuroticism on subjective well-being: happy and unhappy people. J Pers Soc Psychol 1980;38:668-78.

[15] Costa PT, McCrae RR. The NEO-PI personality inventory manual revised. Odessa: Fl: Psychological Assessment Resources; 1990.

[16] Dawson ME, Schell AM, Catania JJ. Autonomic correlates of depression and clinical improvement following electroconvulsive shock therapy. Psychophysiology 1977;14:569-77.

[17] Dawson ME, Schell AM, Filion DL. The electrodermal system. In: Cacioppo JT, Tassinary LG, Bernston GG, editors. Handbook of psychophysiology. 2nd edition New York: Cambridge university press; 2000. p. 200-12.

[18] De Pascalis V, Destro Fiore A, Sparita A. Personality, eventrelated potentials (ERP) and heart rate (HR): an investigation of Gray's theory. Personality and Individual Differences 1996;20:733-46.

[19] De Pascalis V, Speranza O. Personality effects on attentional shift to emotional charged cues: ERP, behavioural and HR data. Personality and Individual Differences 2000;29:217-38.
[20] De Pascalis V, Strippoli E, Riccardi P, Vergari F. Personality, event-related potential (ERP) and hear rate (HR) in emotional word processing. Personality and Individual Differences 2004;36:873-91.

[21] Gomez A, Gomez R. Personality traits of the behavioural approach and inhibition systems: associations with processing of emotional stimuli. Personality and Individual Differences 2002;32:1299-316.

[22] Gray JA, McNaughton N. The neuropsychology of anxiety: an inquiry into the functions of the septo-hippocampal system. second edition Oxford: Oxford University press; 2000.

[23] Gross JJ, Sutton SK, Ketelaar T. Relations between affect and personality: support for the affect-level and affectivereactivity views. Pers Soc Psychol Bull 1998;24:279-88.

[24] Hansenne M, Delhez M, Cloninger RC. Psychometric properties of the temperament and character inventory-revised (TCl-R) in a Belgian sample. J Pers Assess 2005;85:40-9.

[25] Hansenne M, Pitchot X, Gonzalez-Moreno A, Machurot PY, Ansseau M. Tridemensional personality questionnaire and depression. Eur Psychiatr 1998;13:101-3.

[26] Hansenne M, Reggers J, Pinto E, Kjiri K, Ajamier A, Ansseau M. Temperament and character inventory $(\mathrm{TCl})$ and depression. $J$ Psychiatr Res 1999;33:31-6.

[27] Heponiemi T, Keltikangas-Järvinen L, Puttonen S, Ravaja N. BIS/BAS sensitivity and self-rated affects during experimentally induced stress. Personality and Individual Differences 2003;34:943-57.

[28] lacono WG, Lykken DT, Haroian KP, Peloquin LJ, Valentine $\mathrm{RH}$, Tuason VB. Electrodermal activity in euthymic patients with affective disorders: One-year retest stability and the effects of stimulus intensity and significance. J Abnorm Psychol 1984;93:304-11.

[29] Keller MC, Nesse RM. Is low mood an adaptation? Evidence for subtypes with symptoms that match precipitants. J Affect Disord 2005;86:27-35.

[30] Lang PJ, Bradley MM, \& Cluthbert BN. International affective picture system (IAPS): Instruction manual and affective ratings. Technical report A-4, The Center for Research in Psychophysiology, University of Florida; 1999.

[31] Lewinsohn PM, Lobitz WC, Wilson S. "Sensitivity" of depressed individuals to aversive stimuli. J Abnorm Psychol 1973;81:259-63.

[32] Mardaga S, Laloyaux O, Hansenne M. Personality traits modulate skin conductance response to emotional pictures: an investigation with Cloninger's model of personality. Personality and Individual Differences 2006;40:1603-14.

[33] Norris CJ, Larsen JT, Cacioppo JT. Neuroticism is associated with larger and more prolonged electrodermal responses to emotionally evocative pictures. Psychophysiology $2007 ; 44$ : 823-6.

[34] Paelecke-Habermann Y, Pohl J, Leplow B. Attention and executive functions in remitted major depression patients. J Affect Disord 2005;89:125-35.

[35] Raine A, Venables PH, Williams M. Better autonomic conditioning and faster electrodermal half-recovery time at age 15 years as possible protective factor against crime at age 29 years. Dev Psychol 1996;32:624-30.

[36] Richter J, Eisemann M, Richter G. Temperament and character during the course of unipolar depression among inpatients. Eur Arch Psychiatry Clin Neurosci 2000;250:40-7.

[37] Rossignol M, Philippot P, Crommelinck M, Campanella S. Visual processing of emotional expressions in mixed anxiousdepressed subclinical state: An event-related potential study on a female sample. Clin Neurophysiol 2008;38: 267-75.

[38] Rottenberg J, Gross JJ, Gotlib IH. Emotion context insensitivity in major depressive disorder. J Abnorm Psychol 2005;114:627-39. 
[39] Rottenberg J, Kasch KL, Gross JJ, Gotlib IH. Sadness and amusement reactivity differentially predict concurrent and prospective functioning in major depressive disorder. Emotion 2002;2:135-46.

[40] Rottenberg J, Wilhelm FH, Gross JJ, Gotlib IH. Vagal rebound during resolution of tearful crying among depressed and nondepressed individuals. Psychophysiology 2003;40:1-6.

[41] Rusting CL, Larsen RJ. Extraversion, neuroticism, and susceptibility to positive and negative affect: a test of two theoretical models. Personality and Individual Differences 1997;22:607-12.

[42] Silvert L, Delplanque S, Bouwalerh H, Verpoort C, Sequeira $\mathrm{H}$. Autonomic responding to aversive words without conscious valence discrimination. Int J Psychophysiol 2004;53:135-45.

[43] Sigmon S, Nelson-Gray R. Sensitivity to aversive events in depression: Antecedent, concomitant, or consequent? J Psychopathol Behav Assess 1992;14:225-46.
[44] Sloan DM, Strauss ME, Quirk SW, Sajatovic M. Subjective and expressive emotional responses in depression. J Affect Disord 1997;46:135-41.

[45] Suslow T, Dannlowski U, Lalee-Mentzel J, Donges US, Arolt V, Kersting A. Spatial processing of facial emotion in patients with unipolar depression: a longitudinal study. J Affect Disord 2004;83:59-63.

[46] Torrubia R, Avila C, Moltó J, Caseras X. The Sensitivity to Punishment and Sensitivity to Reward Questionnaire (SPSRQ) as a measure of Gray's anxiety and impulsivity dimensions. Personality and Individual Differences 2001;31: 837-62.

[47] Venables PH. Progress in psychophysiology: some applications in a field of abnormal psychology. In: Venables PH, Christie MJ, editors. Research in psychophysiology. London: John Wiley \& sons; 1975 . p. $418-38$. 